\title{
əCYGNSS Ocean Surface Wind Validation in the Tropics
}

\author{
Shakeel Asharaf, ${ }^{\mathrm{a}, \mathrm{b}}$ Duane E. Waliser, ${ }^{\mathrm{b}}$ Derek J. Posselt, ${ }^{\mathrm{b}}$ Christopher S. RuF, ${ }^{\mathrm{c}}$ \\ Chidong Zhang, ${ }^{\mathrm{d}}$ AND AgIE W. Putra ${ }^{\mathrm{e}}$ \\ ${ }^{a}$ Joint Institute for Regional Earth System Science and Engineering, University of California, Los Angeles, \\ Los Angeles, California \\ ${ }^{\mathrm{b}}$ Jet Propulsion Laboratory, California Institute of Technology, Pasadena, California \\ ${ }^{\mathrm{c}}$ University of Michigan, Ann Arbor, Michigan \\ ${ }^{\mathrm{d}}$ NOAA/Pacific Marine Environmental Laboratory, Seattle, Washington \\ ${ }^{\mathrm{e}}$ Agency of Meteorology, Climatology, and Geophysics, Jakarta, Indonesia
}

(Manuscript received 29 May 2020, in final form 4 November 2020)

\begin{abstract}
Surface wind plays a crucial role in many local/regional weather and climate processes, especially through the exchanges of energy, mass, and momentum across Earth's surface. However, there is a lack of consistent observations with continuous coverage over the global tropical ocean. To fill this gap, the NASA Cyclone Global Navigation Satellite System (CYGNSS) mission was launched in December 2016, consisting of a constellation of eight small spacecrafts that remotely sense near-surface wind speed over the tropical and subtropical oceans with relatively high sampling rates both temporally and spatially. This current study uses data obtained from the Tropical Moored Buoy Arrays to quantitatively characterize and validate the CYGNSS derived winds over the tropical Indian, Pacific, and Atlantic Oceans. The validation results show that the uncertainty in CYGNSS wind speed, as compared with these tropical buoy data, is less than $2 \mathrm{~m} \mathrm{~s}^{-1}$ root-mean-square difference, meeting the NASA science mission level-1 uncertainty requirement for wind speeds below $20 \mathrm{~m} \mathrm{~s}^{-1}$. The quality of the CYGNSS wind is further assessed under different precipitation conditions, and in convective cold-pool events, identified using buoy rain and temperature data. Results show that CYGNSS winds compare fairly well with buoy observations in the presence of rain, though at low wind speeds the presence of rain appears to cause a slight positive wind speed bias in the CYGNSS data. The comparison indicates the potential utility of the CYGNSS surface wind product, which in turn may help to unravel the complexities of air-sea interaction in regions that are relatively undersampled by other observing platforms.
\end{abstract}

KEYWORDS: Ocean; Atmosphere-ocean interaction; Wind; Buoy observations; Microwave observations; Remote sensing

\section{Introduction}

Spaceborne measurements have provided unprecedented insights in weather/climate research, advancing our understanding of the complexity of Earth-atmosphere interactions. They have become instrumental in providing comprehensive and reliable information, especially over complex and/or remote regions, e.g., over ocean, where large gaps in data may occur. There is a broad spectrum of satellite data applications, including operational weather forecasting, drought monitoring, and natural disaster assessment. For instance, satellite observations currently play a key role in the initialization of numerical models used for weather/climate forecasting. These forecasts play a decisive role in decision-making in important sectors such as food and water security, energy production, agriculture, human health, and drought early warning.

A major shortcoming of traditional polar-orbiting satellites is their infrequent temporal sampling rate at a given location, which is typically approximately one or two samples per day, depending on their swath width. As a consequence, finescale

\footnotetext{
๑ Denotes content that is immediately available upon publication as open access.
}

Corresponding author: Shakeel Asharaf, shakeel.asharaf@jpl. nasa.gov temporal information is unavailable and the complete evolution of a mesoscale or synoptic process is typically undersampled. If the polar orbits are also sun synchronous, then the observations are also likely to be biased if any systematic diurnal signals exist in the quantity of interest (e.g., wind speed; Waliser and Gautier 1993). The significance of this issue is expected to be regionally dependent, influenced by the strength, character, and phase of diurnal variations.

Apart from these temporal sampling issues, most past and current scatterometers use $\mathrm{C}(4-8 \mathrm{GHz})$ or higher-frequency $\mathrm{Ku}(12-18 \mathrm{GHz})$ bands, which have known performance limitations in rain conditions (Marzano et al. 2000; Weissman et al. 2002; Tournadre and Quilfen 2003; Milliff et al. 2004; Weissman and Bourassa 2008; Portabella et al. 2012). In general, rain can significantly affect the microwave radar signals in three possible ways: 1) attenuation or absorption of the signal when it passes through the rainy atmosphere; 2 ) scattering received by intervening raindrops, leading to a modification in the radar signals; and 3) by altering the roughness of the sea surface either through a direct contact with rain drops or by local downdraft and outflow wind due to rain (Balasubramaniam and Ruf 2020). The effect on sea surface roughness is due to "splashing," which occurs at low winds when the sea surface is calm. When rain strikes a calm water surface, it creates rings, crowns, or stalks, each of which modifies the signal received by the radar, resulting in an overestimate of the wind speed in calm sea 
surface conditions (Draper and Long 2004). Under high wind conditions, the splashing process acts differently. In this case, wind-driven rain can perturb and/or eventually modify the scale of water waves by horizontal momentum transfer (Le Méhauté and Khangaonkar 1990; Weissman et al. 2012). The contribution of horizontal momentum transfer on water waves is mainly dependent on the angle (from the nadir direction) raindrops are falling onto the water surface. For instance, the horizontal rain velocity component often prevails in high wind condition. This may subsequently add to the wind effect, enhancing the amplitude of high-frequency waves (Le Méhauté and Khangaonkar 1990).

Considering these important processes, and the uncertainties in remotely sensing surface wind via radar, the recently launched NASA Cyclone Global Navigation Satellite System (CYGNSS) mission aims to measure near-surface wind speeds over the tropical ocean remotely with relatively higher temporal and spatial sampling rates. CYGNSS consists of eight spacecraft, each carrying L-band receivers tuned to measure the global positioning system (GPS) signals scattered from the ocean surface in the forward direction. As such, the CYGNSS mission is the receiver component of a bistatic radar system for which the GPS constellation are the transmitters. Each spacecraft is designed with one upward and two downward looking antennas (port and starboard), measuring the GPS signals from specular reflection points at a sampling frequency of $1 \mathrm{~Hz}$. Each spacecraft flies in a circular low non-sunsynchronous orbit at $35^{\circ}$ inclination and $520-\mathrm{km}$ altitude allowing coverage of the whole tropics with higher temporal sampling rates than other scatterometers. Because it contains L-band ( $\sim 1.6-\mathrm{GHz}$ frequency or $\sim 19$-cm wavelength) sensors and is sensitive to broader roughness spectra, which include both capillary and gravity waves, CYGNSS is expected to be less affected by rain than $\mathrm{C}$ - or Ku-band scatterometers.

In the early phase of the CYGNSS mission, development and testing of the wind retrieval algorithm, accounting for the variety of anticipated environmental conditions, is the primary task. Since CYGNSS winds are estimated from remote measurements, using a geophysical model function (GMF) that maps CYGNSS backscattered coefficient $\left(\sigma_{0}\right)$ to $10-\mathrm{m}$ wind speed (Ruf and Balasubramaniam 2019), errors in the estimated values are expected. Recently, an overview of CYGNSS wind performance has been presented by Ruf et al. (2019). The emphasis of their study was on the CYGNSS performance relative to NASA level-1 mission requirements, classified into several subcategories such as: spatial and temporal sampling properties; dynamic range and uncertainty of wind speed measurements; and data validation and support for operational data users. Thus, while their results included comparisons versus available in situ measurements, their study did not explore the degree to which each contributing factor [e.g., wind itself, sea surface temperature (SST), stability effects, and other air-sea parameters] is responsible for introducing bias and uncertainties in CYGNSS wind estimates. In this study, we assess the performance of CYGNSS in different oceanic regimes. This includes air-sea meteorological variables at and near the surface and under different convective conditions such as, rain and cold pools through a comprehensive and quantitative evaluation of the CYGNSS derived wind speeds using observations from the research-quality tropical moored buoy arrays.

\section{Data and validation approach}

\section{a. Data}

CYGNSS level-2 v2.1 surface ocean winds, using the algorithm for winds over fully developed seas (FDS), were obtained from the NASA's Jet Propulsion Laboratory (JPL) PO.DAAC data web portal (https://podaac.jpl.nasa.gov/ dataset/CYGNSS_L2_V2.1). The data product provides the time-stamped and spatially averaged wind speed at $25 \mathrm{~km}$ effective resolution that were determined from the delay Doppler mapping (DDM) instrument mounted on the CYGNSS spacecrafts. The reported sample locations refer to the specular points corresponding to the averaged DDMs. It has been found that the transmit power fluctuations by GPS Block type IIF CYGNSS spacecrafts can introduce bias into the L2 wind speed retrievals (Ruf and Balasubramaniam 2019). Version 2.1 calibration, unfortunately, does not apply any correction to fix this power fluctuation issue, and therefore in this version the Block type IIF samples were not used in the evaluation against buoy data (Ruf et al. 2019). In addition, the data points that have a range corrected gain (RCG) value less than three were flagged and not used. The smaller RCGs are often correlated with a high incidence angle and lower signal strength, leading to a higher degree of uncertainty in the wind estimates (Ruf et al. 2016).

Surface wind and rain observations from the tropical moored buoy arrays Prediction and Research Moored Array in the Tropical Atlantic (PIRATA; Bourlès et al. 2008), Research Moored Array for African-Asian-Australian Monsoon Analysis and Prediction (RAMA; McPhaden et al. 2009), and Tropical Atmosphere Ocean (TAO; McPhaden et al. 1998)/Triangle Trans-Ocean Buoy Network (TRITON) were employed as reference data. Buoy measurements are averaged over 60-min periods, and were screened by discarding any missing records as well as data flagged as lower quality and/or with sensor failure. The accuracy for buoy wind speed is $\pm 0.3 \mathrm{~m} \mathrm{~s}^{-1}$ or $3 \%$ (see details at https://tao.ndbc.noaa.gov/ proj_overview/sensors_ndbc.shtml). Wind sensors record sustained winds at sampling frequency of $2 \mathrm{~Hz}$ over a 2-min sampling period. A total of 240 samples were thus averaged to produce 10 -min winds, and then these 10-min winds were averaged to produce hourly winds (K. Grissom, NOAA, 2019, personal communication).

The significant wave height information was obtained from the French Research Institute for Exploitation of the Sea (IFREMER) and Meteo-France implementation of the ECMWF WaveWatch3 (WW3) model. The datasets are publicly available at $0.5^{\circ}$ grid spacing at 3-h intervals (ftp://ftp.ifremer/ww3/ HINDCAST/GLOBAL/).

\section{b. Rain measurement correction for undercatchment}

It has been observed that the rain gauges are susceptible to undercatchment error under windy conditions. For instance, 
the undercatchment error can be as large as $50 \%$ in wind speeds of $12 \mathrm{~m} \mathrm{~s}^{-1}$ (Koschmieder 1934). There are no undercatch corrections applied directly to the data that we have accessed from the NOAA/PMEL FTP site. Therefore, following simple yet efficient approach by Serra et al. (2001), a third-order polynomial fit to the Koschmieder (1934) data was employed to correct the undercatchment for the rain measurements. Note that numerous methods (e.g., Habib et al. 1999; Nešpor and Sevruk 1999) have been (and are still being) proposed for the wind induced rain measurement correction. However, none have been universally accepted. Moreover, most of them are derived from laboratory studies and their applicability in real world (e.g., over oceans) are limited due to a lack of additional information required. For instance, the approach by Nešpor and Sevruk (1999) requires information of rain drop sizes, which is currently not available at the tropical buoy sites. In contrast, the technique by Serra et al. (2001) is much simpler to implement, since it does not require any hydrometeor drop size information. This method has already been applied to the tropical Autonomous Temperature Line Acquisition System (ATLAS) mooring measurements (Serra et al. 2001).

\section{c. Buoy height adjustment}

CYGNSS winds are reported at 10-m heights from the sea surface, whereas the buoy records are available at $\sim 4 \mathrm{~m}$ with some exceptions. To make a direct comparison, buoy winds were adjusted to $10-\mathrm{m}$ height following Monin-Obukhov (M-O) similarity theory as follows:

$$
U_{10}=\frac{u_{*}}{k}\left[\ln \left(\frac{Z_{10}}{z_{0}}\right)-\psi\left(\frac{Z_{10}}{L}\right)\right],
$$

where $U_{10}$ is the buoy scalar wind speeds at the adjusted height $Z_{10}(10 \mathrm{~m}), u_{*}$ the frictional velocity, $L$ the Monin-Obukhov length, $z_{0}$ the surface roughness, $k$ the von Kármán's constant $(\sim 0.4)$, and $\psi$ represents the stability function.

Since satellite winds are derived from the radar backscattered signals, they uniquely respond to changes in sea surface roughness. They are thus more sensitive to the wind stress than the wind speed. Under a neutrally stratified marine boundary layer condition, wind speeds are considered to be uniquely related to satellite winds (Liu 1984). Hence, the buoy actual winds were converted to equivalent neutral winds $\left(U_{10 \mathrm{n}}\right)$ by removing the stability effects as follows:

$$
U_{10 \mathrm{n}}=\frac{u_{*}}{k} \ln \left(\frac{Z_{10}}{z_{o}}\right) .
$$

This can be understood by the fact that when the atmospheric stratification is neutral, the $Z_{10} / L$ tends to zero, and thus the stability function vanishes in Eq. (1). Using an empirical constant value of roughness length, one can readily calculate the reference wind at a desired height. However, this approach does not fully account for the effect of atmospheric stability on wind shear due to its fixed sea surface condition and the assumption of uniform fluxes in the surface layer. Previous studies suggest that a fixed roughness length can introduce additional uncertainty in the adjusted wind values. For instance, Mears et al. (2001) reported the mean difference between these two methods for adjusted wind values is around $0.12 \mathrm{~m} \mathrm{~s}^{-1}$ (standard deviation $=0.17 \mathrm{~m} \mathrm{~s}^{-1}$ ). Peng et al. (2013) later noticed high biases (ranges from 0.11 to $0.17 \mathrm{~m} \mathrm{~s}^{-1}$ ) from the simple method. Therefore, to compute the equivalent neutral winds, the bulk aerodynamic algorithm Coupled Ocean-Atmosphere Response Experiment (COARE) version 3.6 (Edson et al. 2013; Fairall et al. 2003) was used in this study. Specifically, the buoy measured air temperature, sea surface temperature, relative humidity, and surface wind speeds were provided as input to the algorithm to determine the equivalent neutral winds at the $10 \mathrm{~m}$ height. The COARE algorithm is the successor to the Liu-Katsaros-Businger (LKB) model (Liu et al. 1979), and is one of the most widely used bulk aerodynamic algorithms in the world. The algorithm has notable features, including the warm/cool-layer parameterizations that compute the skin correction to SST. To use the cool-layer correction, one requires additional information such as radiation data. Because the buoys measure bulk SST, and the radiation records are sparse in the tropics, a $0.2^{\circ} \mathrm{C}$ cool offset in SST following Cronin et al. (2006) was implemented to the cool-layer correction. In addition, the warm-layer correction was turned off in the current setup, as Cronin et al. (2006) showed a limited effect with the correction (during JanuaryMay) with the COARE 3.0 algorithm in the tropics.

\section{d. Collocation method}

CYGNSS derived FDS surface winds during the period spanning 18 March 2017 to 31 August 2019 were validated against the buoys. CYGNSS winds were matched to buoy measurements within $25 \mathrm{~km}$ and $\pm 30 \mathrm{~min}$ of buoy locations and times (buoy time stamp refers to the middle of the hourly averaging period), and collocation was performed via an inverse-weighting scheme that accounts for both space and time between the measurements (Boutin and Etcheto 1990). Here the choice of the $25-\mathrm{km}$ spatial threshold is motivated by the fact that the effective footprint size of CYGNSS measurement is approximately $25 \mathrm{~km} \times 25 \mathrm{~km}$ over the ocean (Ruf et al. 2019). Since CYGNSS observes at a 1-Hz frequency, it is likely that multiple CYGNSS specular points fall near a buoy location within the $25-\mathrm{km}$ threshold and $\pm 30 \mathrm{~min}$. Our collocation approach included all of the specular points along the specular point track that were within the spatial and temporal thresholds. A total of 83 buoys were available after the matchups described here. This in turn leads to an aggregated sample size of 24261 time-space matchup points after applying the CYGNSS data quality flags.

\section{e. Data processing for the residual dependency analysis}

A quadratic fit was administered on the residual winds (CYGNSS - buoy) versus buoy winds data following Liu (1984). Then these data were subtracted from the CYGNSS data to remove the wind dependency on the CYGNSS-derived wind biases. To detect whether the dependency (in terms of correlation) is statistically robust, we employed an effective sample size based approach that accounts for lag-1 autocorrelation in the data series (Bretherton et al. 1999). In this analysis, the null hypothesis would be rejected if the value is 
at the $5 \%$ significance level $(p$ value $\leq 0.05)$. An air-sea temperature-based analysis of stability is limited in that it does not incorporate wind information. Hence, the stability effect on the CYGNSS winds were examined through the bulk Richardson number (BRi), following Eq. (1) in Ebuchi et al. (2002). The BRi is essentially a ratio of buoyancy to shear production of turbulence, indicating a dynamic condition of the atmosphere.

\section{f. Cold-pool detection}

Convectively driven cold pools are sources of local wind variability (gustiness), and are generally associated with downdrafts and evaporation of rain beneath convective systems. Previous studies have reported the surface characteristics and behaviors of meteorological variables related to cold pools (e.g., Provod et al. 2016; Engerer et al. 2008; Eastin et al. 2012; Yokoi et al. 2014; Whiteman et al. 2001; S. S. Chen et al. 2016; de Szoeke et al. 2017; Chandra et al. 2018). These studies reported rapid decreases in air temperature and humidity, along with drastic changes in wind directions, wind speeds, and other near-surface meteorological variables as cold pools pass over surface observing locations. In this study, cold pools were detected at the buoy locations, following Provod et al. (2016) and Yokoi et al. (2014), as cases when the air temperature drops $1.5^{\circ} \mathrm{C}$ or more over $1 \mathrm{~h}$ or $2.0^{\circ} \mathrm{C}$ or more over $2 \mathrm{~h}$ (Kilpatrick and Xie 2015). To ensure that a cold pool is driven by a convective system, infrared brightness temperature (equivalent blackbody temperature) from a merged 4-km satellite product (Janowiak et al. 2017) was required to be less than $241 \mathrm{~K}$ within $100 \mathrm{~km}$ (detection of deep convection). It is known that shallow convection can also generate cold pools (Rowe and Houze 2015). To remove the ambiguity, "no-cold-pool" events are defined as periods with no such changes in temperatures at the buoy locations.

\section{Results and discussions}

\section{a. Direct comparison}

In this section, comparisons between surface winds from CYGNSS and the buoys are presented at both global and regional levels.

\section{1) GLOBAL PERFORMANCE ANALYSIS}

A general agreement between collocated buoy and CYGNSS winds can be seen in the figure (Fig. 2a, which shows their global scatterplot). The highest density of points (reddish colors) lies along the 1:1 line, which is concentrated within the wind range of $5-7 \mathrm{~m} \mathrm{~s}^{-1}$. However, CYGNSS winds can be substantially higher than the buoy winds in the same range. The mean bias $\mu$ $\left(0.27 \mathrm{~m} \mathrm{~s}^{-1}\right)$ is computed as an average over all buoys; its low value is due in part to compensating errors. For instance, over the far east Pacific and Atlantic Oceans, the biases are underestimated in most of the buoys, whereas in the central and west Pacific, as well as the Indian Ocean, they are highly overestimated (not shown). When biases are computed for individual buoys, they can be larger than $1.5 \mathrm{~m} \mathrm{~s}^{-1}$, especially in the northern and southern sections of central equatorial Pacific belt. The root-mean-square difference (RMSD) over all buoys is $1.86 \mathrm{~m} \mathrm{~s}^{-1}$, which is about $77 \%$ of the standard deviation of the buoy measurements $\left(\sigma_{b}=2.41 \mathrm{~m} \mathrm{~s}^{-1}\right)$. Together taking into account the buoy wind accuracy of $3 \%$ and assuming negligible inherent matchup uncertainty, the upper bound of the CYGNSS retrieval uncertainty $\left(<20 \mathrm{~m} \mathrm{~s}^{-1}\right.$ for CYGNSS wind case) is found to be $\sim 1.8 \mathrm{~m} \mathrm{~s}^{-1}$. This value is greater than the previously reported value of Ruf et al. (2019). It must be noted that the matchup samples are relatively one year longer in the present analysis than the previous buoy validation analysis. If the time period is considered to be the same as prescribed by Ruf et al. (2019) then the RMSD value is found to be in good agreement with their findings irrespective of the different bulk algorithms (Zeng et al. 1998) used in the two studies. While the overall shapes of the buoy and CYGNSS wind probability distributions are similar, there are some discrepancies, especially at the higher and lower wind speeds, where the wind comparisons exhibit the greatest differences (the histogram figure in the inset plot of Fig. 2a). For example, at the lower (higher) wind speeds, CYGNSS has higher (lower) frequency of occurrence compared to the buoys. Moreover, the results from CYGNSS yield a relatively higher number of samples in the higher wind speed range than the buoy measurements, which is partly due to the buoy winds rarely exceeding speeds of $15 \mathrm{~m} \mathrm{~s}^{-1}$ in the tropics (Yu and Jin 2012).

The analysis of the dependence of the wind speed difference (CYGNSS-buoy) on the wind speed itself (represented here by the buoy) shows that the bias is small and positive (i.e., $\sim 0.5 \mathrm{~m} \mathrm{~s}^{-1}$ ) for wind speeds below $\sim 3 \mathrm{~m} \mathrm{~s}^{-1}$, near zero in the buoy wind range of approximately $3-9 \mathrm{~m} \mathrm{~s}^{-1}$, and negative at higher wind speeds, approaching approximately $-3 \mathrm{~m} \mathrm{~s}^{-1}$ at speeds near $15 \mathrm{~m} \mathrm{~s}^{-1}$ (Fig. 3a). The RMSD values remain below $2 \mathrm{~m} \mathrm{~s}^{-1}$ in the wind speed range of $\sim 1-10 \mathrm{~m} \mathrm{~s}^{-1}$. The $95 \%$ error bars show that the confidence in the estimated bias values at extreme wind speeds has low statistical significance due to the relatively small sample size. Detailed statistical information at different buoy wind range conditions are given in Table 1. Here the choices of low and high winds criteria were based on two thresholds: 1) below the lower tercile and 2) above the 95 th percentile of the aggregated buoy wind distribution. The moderate buoy-based wind denotes the values between these two wind thresholds.

\section{2) REgIONAL PERFORMANCE ANALYSIS}

Since the tropical oceans exhibit large spatial and temporal variations in meteorological conditions, they are divided into three oceanic subregions: the Atlantic, Pacific, and Indian Oceans, as depicted in Fig. 1. These subregions provide aggregate representations of different types of background climatology and variability. For instance, the Atlantic Ocean is characterized by a strong seasonal cycle. The Pacific Ocean is the largest of the world's oceans and exhibits heterogeneous SST variations, both latitudinally and from east to west. The Indian Ocean is the warmest ocean in the world, and contains the core of the large-scale tropical warm pool. Thus, the wind speeds of these subregions, compared with the observations, will indicate the performance of CYGNSS under different natural variability conditions. 
TABLE 1. Global and regional summary of statistical parameters [matchup sample size $(N)$, mean bias, RMSD, and correlation coefficient (Corr.)] of wind speed between CYGNSS and buoy at different buoy-measured wind ranges.

\begin{tabular}{|c|c|c|c|c|c|c|c|c|c|c|c|c|c|c|c|c|}
\hline \multirow[b]{3}{*}{ Coverage } & \multicolumn{16}{|c|}{ Buoy wind range $\left(\mathrm{m} \mathrm{s}^{-1}\right)$} \\
\hline & \multicolumn{4}{|c|}{ Low $\left(U_{10 \mathrm{n}}<5\right)$} & \multicolumn{4}{|c|}{ Moderate $\left(5 \leq U_{10 \mathrm{n}} \geq 12\right)$} & \multicolumn{4}{|c|}{$\operatorname{High}\left(U_{10 \mathrm{n}}>12\right)$} & \multicolumn{4}{|c|}{ Full } \\
\hline & $N$ & Bias & RMSD & Corr. & $N$ & Bias & RMSD & Corr & $N$ & Bias & RMSD & Corr. & $N$ & Bias & RMSD & Corr. \\
\hline Global & 6418 & 0.5 & 1.73 & 0.50 & 17646 & 0.21 & 1.89 & 0.56 & 197 & -2.05 & 3.07 & 0.17 & 24261 & 0.27 & 1.86 & 0.76 \\
\hline Indian & 1538 & 0.29 & 1.72 & 0.48 & 3366 & 0.19 & 2.00 & 0.63 & 124 & -1.62 & 2.75 & 0.06 & 5028 & 0.17 & 1.94 & 0.80 \\
\hline Pacific & 3696 & 0.54 & 1.71 & 0.52 & 10181 & 0.34 & 1.86 & 0.53 & 29 & -2.36 & 3.18 & 0.18 & 13906 & 0.39 & 1.82 & 0.75 \\
\hline Atlantic & 1184 & 0.64 & 1.84 & 0.43 & 4099 & -0.08 & 1.89 & 0.56 & 44 & -3.03 & 3.76 & 0.43 & 5327 & 0.05 & 1.90 & 0.70 \\
\hline
\end{tabular}

Scatterplots produced for each region show a general agreement along the diagonal 1:1 line, though larger differences are observed at higher wind speeds in the Atlantic and Pacific Oceans compared to the Indian Ocean (Fig. 2b). However, compared to the other two regions (Figs. 2c,d), the Indian Ocean shows relatively less density in the data points along the 1:1 line. Although CYGNSS shows similar error behavior in all three ocean regions, the RMSD values are different in the three regions (Fig. 3). The Indian Ocean exhibits slightly larger overall RMSD value $\left(1.94 \mathrm{~m} \mathrm{~s}^{-1}\right)$, which is more pronounced $\left(2 \mathrm{~m} \mathrm{~s}^{-1}\right)$ at the moderate wind speeds, than the Atlantic and Pacific Oceans (1.90 and $1.82 \mathrm{~m} \mathrm{~s}^{-1}$, respectively). In contrast, at the extreme winds, the higher RMSD values ( $1.84 \mathrm{~m} \mathrm{~s}^{-1}$ for low and $3.76 \mathrm{~m} \mathrm{~s}^{-1}$ for high wind speeds) are observed in the Atlantic Ocean. It can be seen from Fig. 3 that the wind speed distributions for the three oceans show similar shapes at the higher and lower wind speed ranges. However, the Indian ocean exhibits a slightly flatter distribution (Fig. 2b) than the other two oceans (Figs. 2c,d)-indicating a more uniform distribution of low to moderate wind values. The number of extreme wind events (i.e., winds in the 13 and $14 \mathrm{~m} \mathrm{~s}^{-1}$ in Fig. 3) is found to be larger in the Indian Ocean than in the Atlantic Ocean. It is worth mentioning that the CYGNSS data are more sensitive and experience relatively larger errors at the extreme wind speeds (Fig. 3 and Table 1).

\section{b. Effects of the air-sea state}

Exploring the effects of the atmosphere-ocean conditions on the observed wind speeds is crucial. Biases introduced by air-sea state and exchange processes have the potential to introduce biases into the applications of wind-derived products, such as in the estimation of surface heat fluxes (Crespo et al. 2019). To assess the potential impact of these conditions on the matchups, wind difference residuals are regressed against a number of air-sea conditions. Specifically, Fig. 4 and its statistical summary on each panel show the regression slope and correlation values obtained from CYGNSS-buoy wind residuals against variables such as air temperature, SST, and relative humidity, considering the tropics as a whole, and separately for the three ocean subregions. The regression statistics reveal that no specific air-sea condition systematically accounts for much of the remaining residual error (Fig. 4). Furthermore, the error dependency on the air temperature (Figs. 4e-h) and SST (Figs. 4a-d) has nearly the same slope magnitude in all three oceans. However, the dependency on SST is slightly greater in the Indian Ocean (Fig. 4a) than that of the Atlantic and Pacific Oceans (Figs. 4b,c), where it shows a small (only $1 \%$ explained variance) but statistically significant negative relationship with the wind residuals (decreasing rate $0.16 \mathrm{~m} \mathrm{~s}^{-1}$ with increase in $1^{\circ} \mathrm{C} \mathrm{SST}$ ). One can notice that the sample distributions between Figs. $4 \mathrm{i}-1$ and Figs. $4 \mathrm{~m}-\mathrm{p}$ are not consistent. The nearsurface atmosphere is typically unstable to near neutrally stratified over the global tropical oceans. As such, SST is typically slightly larger than the air temperature, and most of the samples in Figs. 4i-l are concentrated near values of $T_{\text {air }}-\mathrm{SST}$ near, and slightly smaller than, zero. If the air were perfectly still (no wind), then one would indeed expect the relative humidity values to approach $100 \%$ as the air-sea temperature

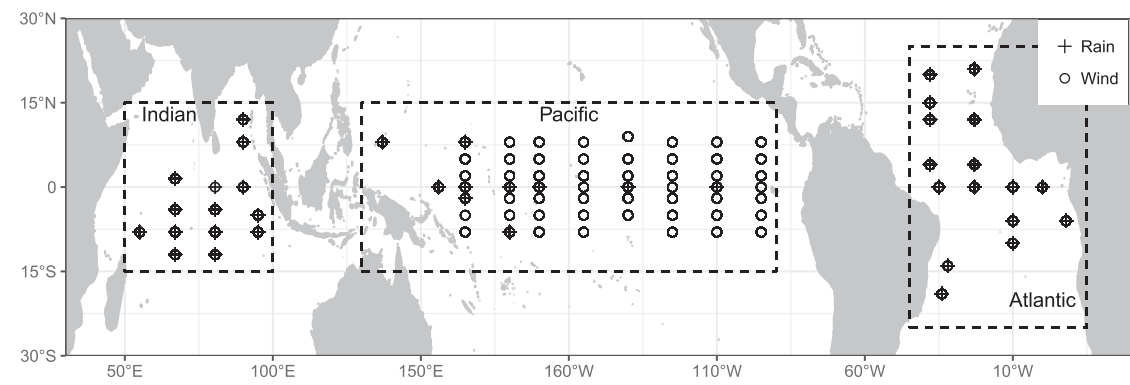

FIG. 1. The tropical moored-buoy array: Prediction and Research Moored Array in the Tropical Atlantic (PIRATA), Research Moored Array for African-Asian-Australian Monsoon Analysis and Prediction (RAMA), and Tropical Atmosphere Ocean (TAO)/Triangle Trans-Ocean Buoy Network (TRITON) for winds (circles) and rainfall (plus signs). More details on the tropical buoys are given on the NOAA/PMEL website (www.pmel.noaa.gov/ gtmba/mission). 

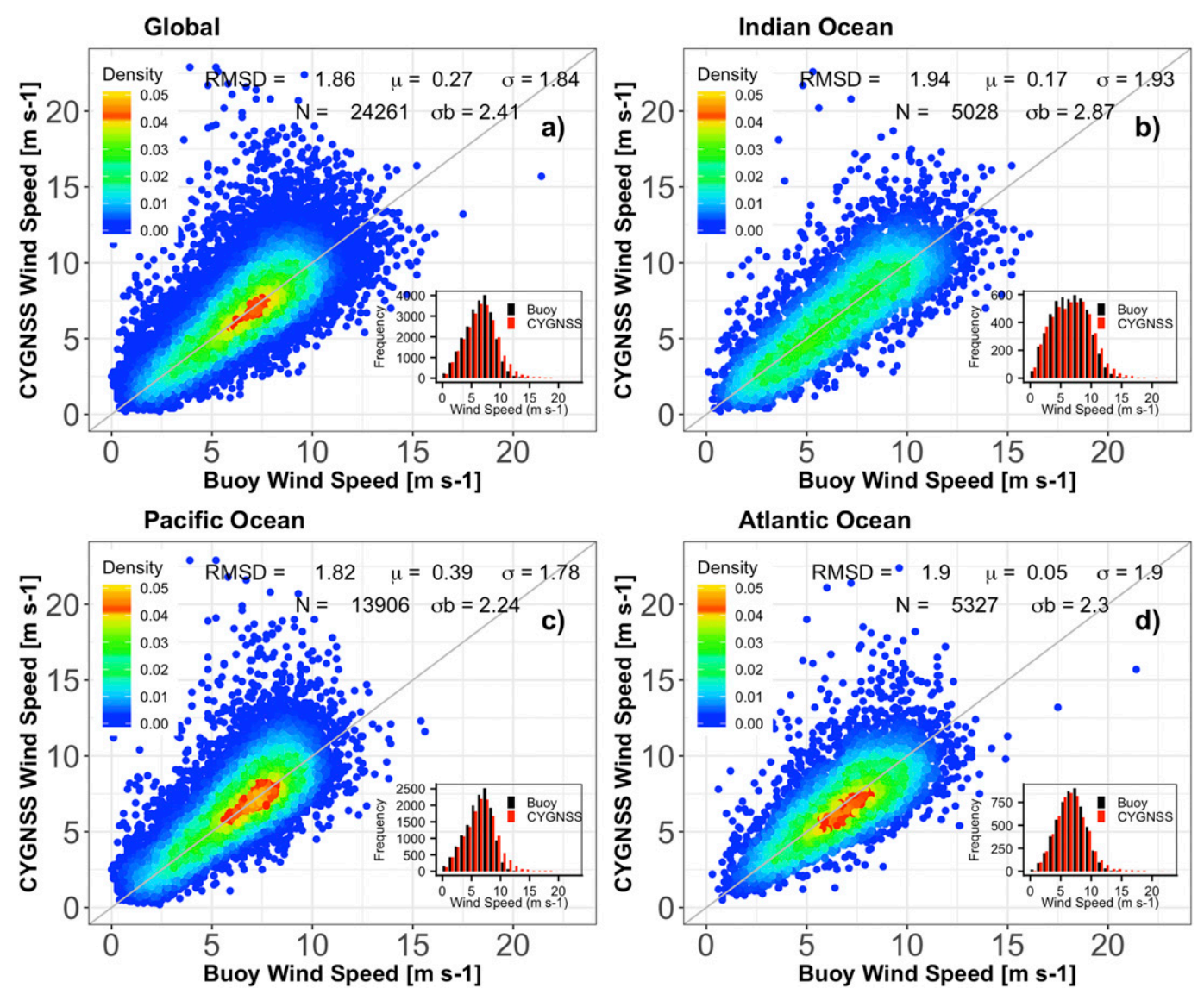

FIG. 2. Two-dimensional density plot of collocated CYGNSS and tropical buoy wind speeds: (a) global tropics, (b) Indian Ocean, (c) Pacific Ocean, and (d) Atlantic Ocean. The diagonal gray line is the 1:1 agreement. The statistical parameters RMSD, $\mu, \sigma, \sigma_{b}$, and $N$ are the root-mean-square difference, mean bias (CYGNSS-buoy), standard deviation of the difference (CYGNSS-buoy), standard deviation of buoy winds, and the total sample size of the collocated CYGNSS and buoy wind data, respectively. Inset figures show the surface wind histograms (bin width: $1 \mathrm{~m} \mathrm{~s}^{-1}$ ) for both CYGNSS and buoys.

difference approaches zero. However, this is rarely, if ever, the case. In the presence of even slight wind, there will be mixing between the near-surface air and the air higher in the boundary layer, causing RH values to be less than $100 \%$.

The dependency analysis is also performed after bin averaging the analyzed air-sea data (Fig. 5). Over an SST range of $20^{\circ}-27^{\circ} \mathrm{C}$, the biases in CYGNSS winds are found to be almost independent of SST change (Fig. 5a). After exceeding the $27^{\circ} \mathrm{C}$ SST, a negative trend emerges that tends to be steeper for the Atlantic Ocean. Because the negative slopes were prominent mostly at warmer SST values $\left(\sim 27^{\circ} \mathrm{C}\right)$ and the Indian Ocean has predominantly warmer SST relative to the other ocean basins (as revealed from the matchup data points shown in Fig. 4a), the SST dependency is relatively stronger in the Indian ocean compared to the Atlantic and Pacific Oceans (Fig. 5a). The SST sensitivity of the CYGNSS winds can be related to the $\sigma_{0}$ relation with the Fresnel coefficient (Ruf et al. 2016) that incorporates the dielectric parameter of seawater, a function of temperature and/or salinity. A similar pattern appears to be found for the air temperature (Fig. 5b), though below $\sim 27^{\circ} \mathrm{C}$, the Indian ocean exhibits a larger departure in bias from the remaining two seas.

Although we find no robust wind bias dependency with respect to relative humidity, a slight increasing trend with increasing moisture content can be seen in all regions (Fig. 5c). Since there are few points with large values of relative humidity, no conclusions can be drawn about possible correlations between the quality of the CYGNSS wind speed estimates and the atmospheric water vapor content.

It is possible that the temperature and SST dependencies may be related to the near-surface stability. The equivalent neutral wind is assumed to be free from the stability effects due to its direct relation to a given surface stress when the atmosphere is neutrally stratified (Liu 1984). If stability effects on the wind profile are not correctly specified, it is probable that scatterometer winds will have systematic stability-dependent errors. Figure 5d shows the bias dependency on the air and sea surface temperature difference. The differences between the air and sea surface in general reflects the atmospheric stratification. When the sea surface temperature is larger than the air 

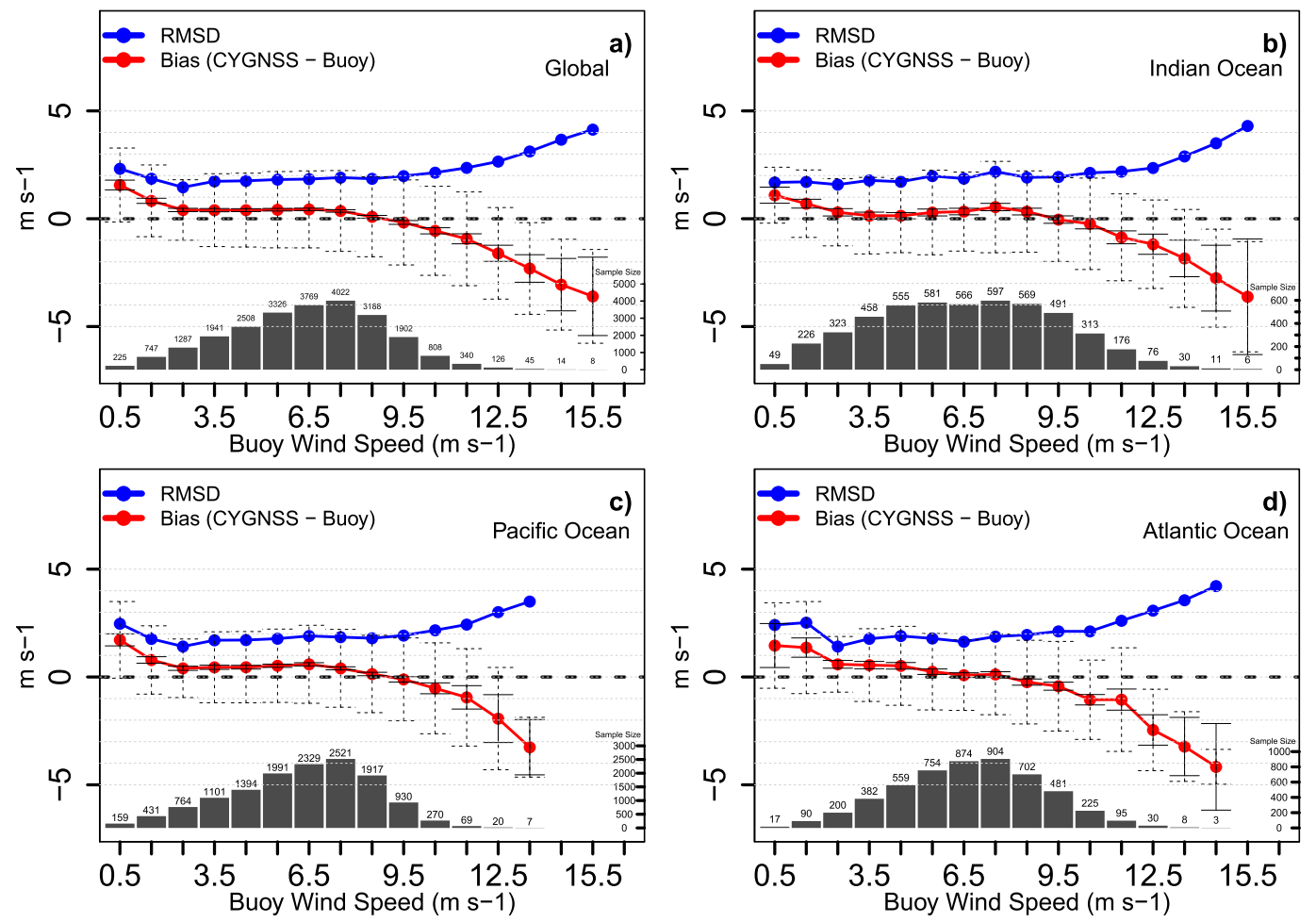

FIG. 3. RMS (blue line) and mean (red line; CYGNSS - buoy) difference between collocated buoy and CYGNSS wind speeds as a function of buoy wind speed: (a) global tropics, (b) Indian Ocean, (c) Pacific Ocean, and (d) Atlantic Ocean. The solid error bars correspond to the $95 \%$ confidence limit, whereas the dashed error bars are the standard deviation. These metrics were computed over a $\pm 0.5 \mathrm{~m} \mathrm{~s}^{-1}$ bin width for every $1 \mathrm{~m} \mathrm{~s}^{-1}$ buoy wind speed. Dashed horizontal lines tick the $y$ axis at a $1 \mathrm{~m} \mathrm{~s}^{-1}$ wind interval. The gray bars and label on top of each bar indicate the sample size in each group of $\pm 0.5 \mathrm{~m} \mathrm{~s}^{-1}$ bin width.

temperature, the atmosphere is considered to be unstable; whereas, in the opposite case (air temperature is greater than SST), the atmosphere is considered to be stable. From Fig. 5d, it can be seen that the bias is positive and relatively large for both unstable and stable stratification, albeit the sampling uncertainties are larger at the extrema of the range of values. In contrast, the dependence on air-sea temperature difference decreases and approaches to a minimum for slightly unstable conditions $\left(T_{\text {air }}-\mathrm{SST} \sim-1.0^{\circ} \mathrm{C}\right.$; Fig. $\left.5 \mathrm{~d}\right)$. The features are in agreement with those presented in Ebuchi et al. (2002) and Liu (1984). The matchup samples are further categorized by aggregating into four different seasons (fall, summer, winter, spring) for each of the four regions (global, Indian, Pacific, Atlantic). Based on these samples, we find that the stable atmosphere, i.e., the positive temperature gradient between $T_{\text {air }}$ and SST ( $T_{\text {air }}-$ SST), frequently occurs during the summer season in all three ocean basins (not shown). Under the stable atmospheric condition (i.e., $T_{\text {air }}>\mathrm{SST}$ ) and considering the four seasons, the mean bias between CYGNSS and buoy winds is largest for the summer season $\left(0.9 \mathrm{~m} \mathrm{~s}^{-1}\right.$ with the above zero $70 \%$ of the total number of samples) over the Indian ocean. In contrast, the maximum wind biases are encountered in the fall and winter seasons for the Atlantic ocean, which are $1.18 \mathrm{~m} \mathrm{~s}^{-1}$ (62\% samples above zero) and $1.12 \mathrm{~m} \mathrm{~s}^{-1}$ (69\% samples above zero), respectively. In the Pacific ocean, the leading mean biases are for winter $\left(0.9 \mathrm{~mm} \mathrm{~s}^{-1}\right.$ with $70 \%$ positive samples $)$ and the spring $\left(0.81 \mathrm{~m} \mathrm{~s}^{-1}\right.$ with $70 \%$ positive samples $)$ seasons.

Figure 6 shows that the BRi values are mostly negative with few positive, indicating atmosphere is predominantly unstable to nearly neutral stratified. CYGNSS appears to be biased high in unstable conditions (Fig. 6). Previous studies suggest that unstable conditions favor vertical exchange processes that eventually increase the roughness of the sea surface, contributing to an increase in surface scattering of microwave radiation (McCarty and Churnside 2016; Quilfen and Bentamy 1994). In the present analysis, when wind is incorporated in the analysis of stability, the positive bias in the CYGNSS wind estimates attains its minimum value when the near-surface atmosphere is close to neutral conditions. While the number of data samples are very small, a slight increasing trend in bias is observed when the atmosphere moves from neutral to more stable (Fig. 6). The patterns are aligned with the portion of Fig. $5 \mathrm{~d}$ for which the air temperature becomes warmer than the SST.

\section{c. Rain influence}

As mentioned above, rain may affect scatterometer signals, especially at higher frequencies. Though it is expected that the influence of rain on the L-band CYGNSS signal should be minimal, it is possible that in light wind and heavy rain 

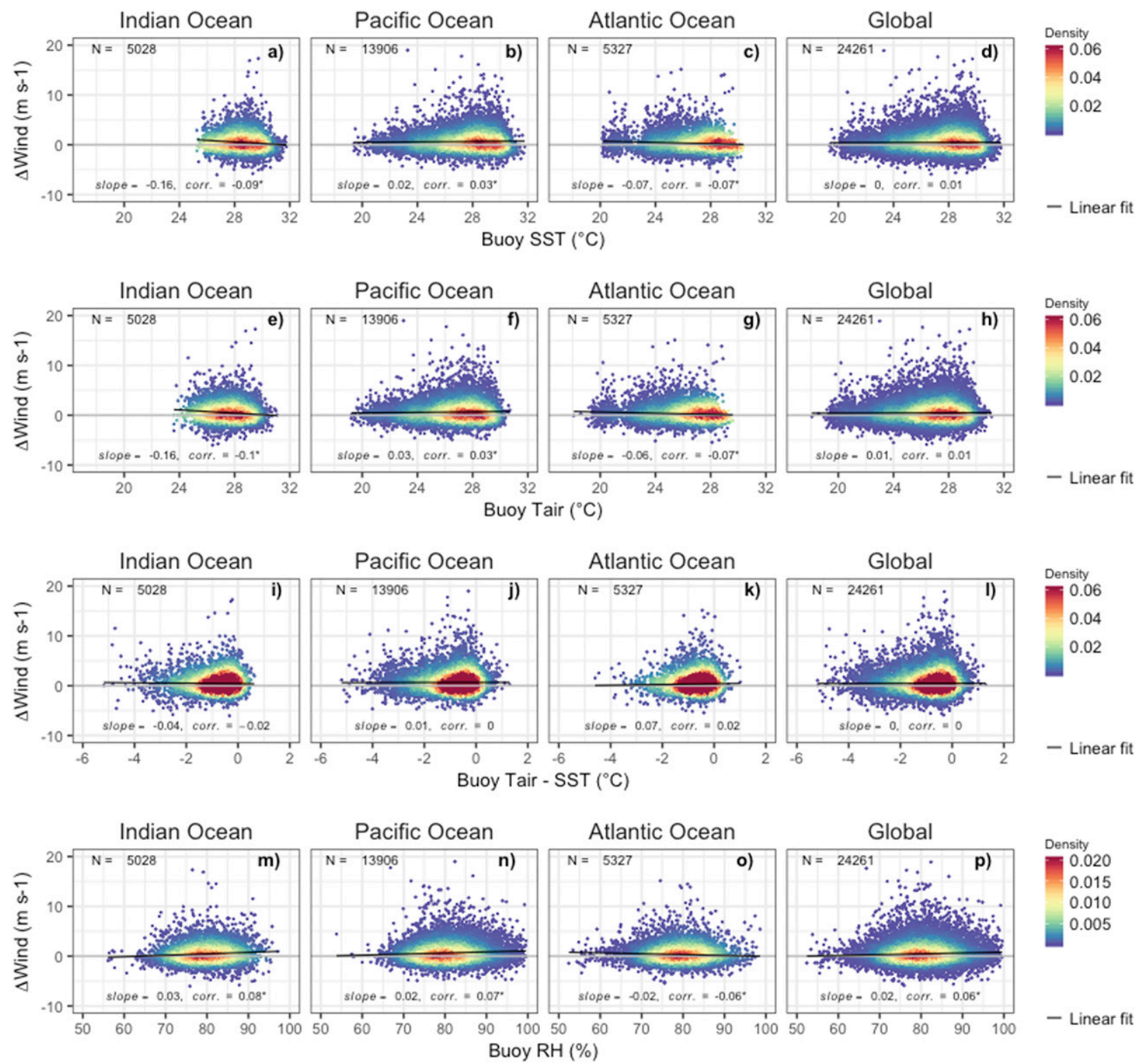

FIG. 4. Two-dimensional density plot of wind difference ( $\Delta$ refers to CYGNSS - buoy) as function of buoy measured (a)-(d) sea surface temperature (SST; in $\left.{ }^{\circ} \mathrm{C}\right),(\mathrm{e})-(\mathrm{h})$ air temperature $\left(T_{\text {air }}\right.$; in $\left.{ }^{\circ} \mathrm{C}\right),(\mathrm{i})-(\mathrm{j})$ difference between $T_{\text {air }}$ and SST (in $\left.{ }^{\circ} \mathrm{C}\right)$, and (m)-(p) relative humidity (in \%). Correlation and slope of linear fit of the wind speed residuals (CYGNSS - buoy) with the atmospheric and oceanic variables at global and regional scales are added in each panel. The 95\% significance level (Bretherton et al. 1999) of the correlation coefficient is indicated by an asterisk., and $N$ is the total sample size of the collocated CYGNSS and buoy wind data. The best-fit linear regression line onto the scatterplot is marked by a solid black line.

conditions there may be an effect on the bias and RMSD of the CYGNSS wind. In particular, rain-induced waves modulate the sea surface roughness and may introduce additional errors in the wind retrieval process by altering the signals scattered from the sea surface. Recently Balasubramaniam and Ruf (2020) examined the rain effects on CYGNSS normalized backscattered coefficients and found out that the rain induced sea surface roughening effect is significantly stronger than the rain-based attenuation of the GPS signal. Because the rain effects are likely to be larger at low wind speeds, we divide our analyses into two wind speed ranges (following Asgarimehr et al. 2018); one for wind speeds less than or equal to $6 \mathrm{~m} \mathrm{~s}^{-1}$ and the other for wind speeds greater than $6 \mathrm{~m} \mathrm{~s}^{-1}$. Before conducting the rain analysis, we removed the wind dependency on CYGNSS residuals. Additionally, we performed the same rain effect analysis on the low wind values (i.e., $\leq 6 \mathrm{~m} \mathrm{~s}^{-1}$ ) that did not exceed the lower tercile value $(1.61 \mathrm{~m})$ of the collocated significant wave height distribution. Thus, this analysis isolates not only relatively lower wind speeds, but also relatively quiet seas in terms of surface wave activity. The presence of high 

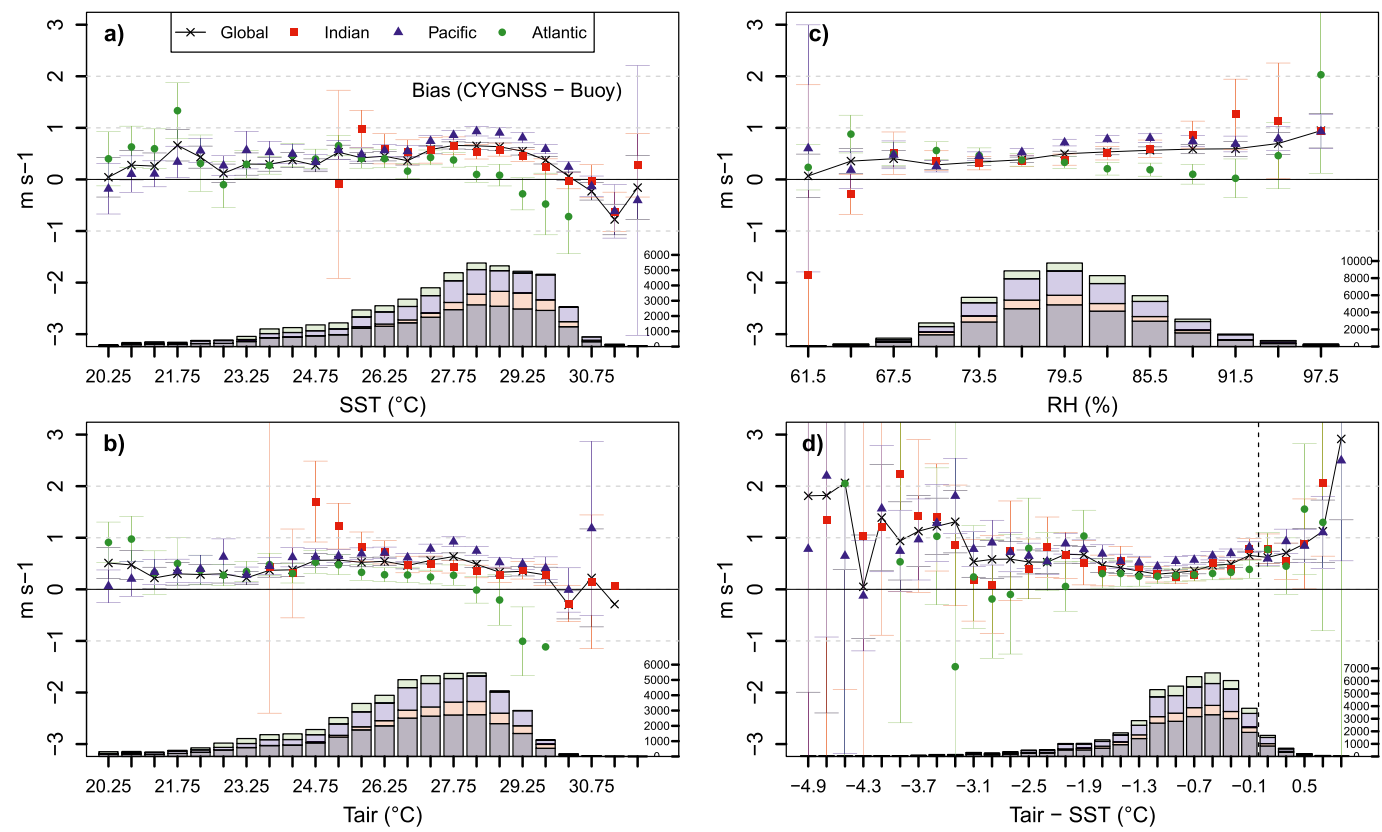

FIG. 5. Wind bias (CYGNSS - buoy) as function of buoy measured for global and regional oceans: (a) SST (bin width: $\left.\pm 0.25^{\circ} \mathrm{C}\right)$, (b) air temperature $\left(T_{\text {air }}\right.$, bin width: $\left.\pm 0.25^{\circ} \mathrm{C}\right),(\mathrm{c})$ relative humidity $(\mathrm{RH}$, bin width: $\pm 1.5 \%)$, and (d) difference between $T_{\text {air }}$ and SST (bin width: $\pm 0.1^{\circ} \mathrm{C}$ ). The error bars correspond to the $95 \%$ confidence limit estimated via bootstrap (random sampling of the dataset is 1000 times with replacement). The stacked bars in light colors (gray, red, blue, and green represent the global, Indian, Pacific, and Atlantic Oceans, respectively) indicate the matchup sample size.

wave activity can alter the rain effect on the backscattered signals, especially when the wind is misaligned with the wave propagation direction.

Figure 7 shows the influence of rain on the wind residuals at wind speeds less than (Figs. 7a,b) and greater than (Figs. 7c,d) $6 \mathrm{~m} \mathrm{~s}^{-1}$. One can observe from the figure that CYGNSS has a small positive bias that increases with rain rate at low wind speeds (Fig. 7b). This increase in bias with rain rate appears to be present for low and high significant wave heights. The RMSD values for low wind speeds (Fig. 7a) are significantly higher in the presence of rain (e.g., $R>1.0$ ) than when little to no rain is present $\left(R<0.1 \mathrm{~mm} \mathrm{~h}^{-1}\right)$. We do note, however, that the sampling uncertainties are larger at higher precipitation rates (especially when the dataset is restricted to low-wave conditions), as can be seen from the large error bars in the RMSD values (Fig. 7a). The positive trend with precipitation rate in the wind RMSD and bias at low winds can be related to the expected predictions of weak diffuse scattering model for winds below $\sim 5-6 \mathrm{~m} \mathrm{~s}^{-1}$ (Zavorotny and Voronovich 2000). Moreover, the current calibration does not account or correct for rain induced attenuation (Balasubramaniam and Ruf 2018). At wind speeds greater than $6 \mathrm{~m} \mathrm{~s}^{-1}$, the effect of rain on the RMSD and bias is relatively small (Figs. 7c,d).

\section{d. Performance in cold pools}

Cold pools occur more frequently over the Indian and west Pacific regions where deep convection with much larger cloud cover is common. The collocated sample density of the detected cold pools is thus larger over the Indian and adjoining west Pacific regions than over the east Pacific and the Atlantic Oceans (not shown here). Examining the cold-pool sample, relative to no-cold-pool (Fig. 8a), shows that the CYGNSS wind speeds exhibit RMSD errors $\sim 34 \%$ higher during coldpool events (RMSD $\sim 2.34 \mathrm{~m} \mathrm{~s}^{-1}$ ) than no-cold-pool events (RMSD $\sim 1.75 \mathrm{~m} \mathrm{~s}^{-1}$ ). Note that the sample size for the coldpool cases is relatively small compared to no-cold-pool cases, though the differences in RMSD values are statistically

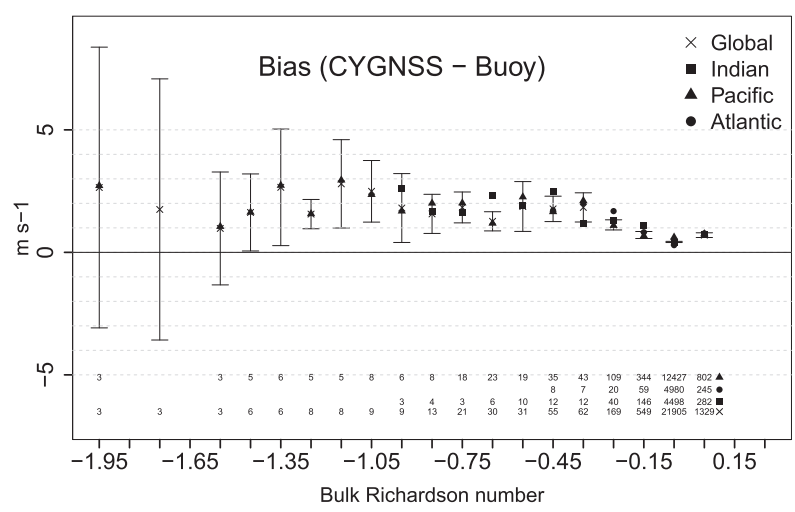

FIG. 6. Wind bias (CYGNSS - buoy) as function of buoy derived bulk Richardson number (BRi, bin width: \pm 0.05$)$ for global and regional tropical seas. The error bars (for global tropics only) correspond to the $95 \%$ confidence limit estimated by the bootstrapping approach. Collocated sample size in each bin for the analyzed oceans is given by numbers at bottom. 

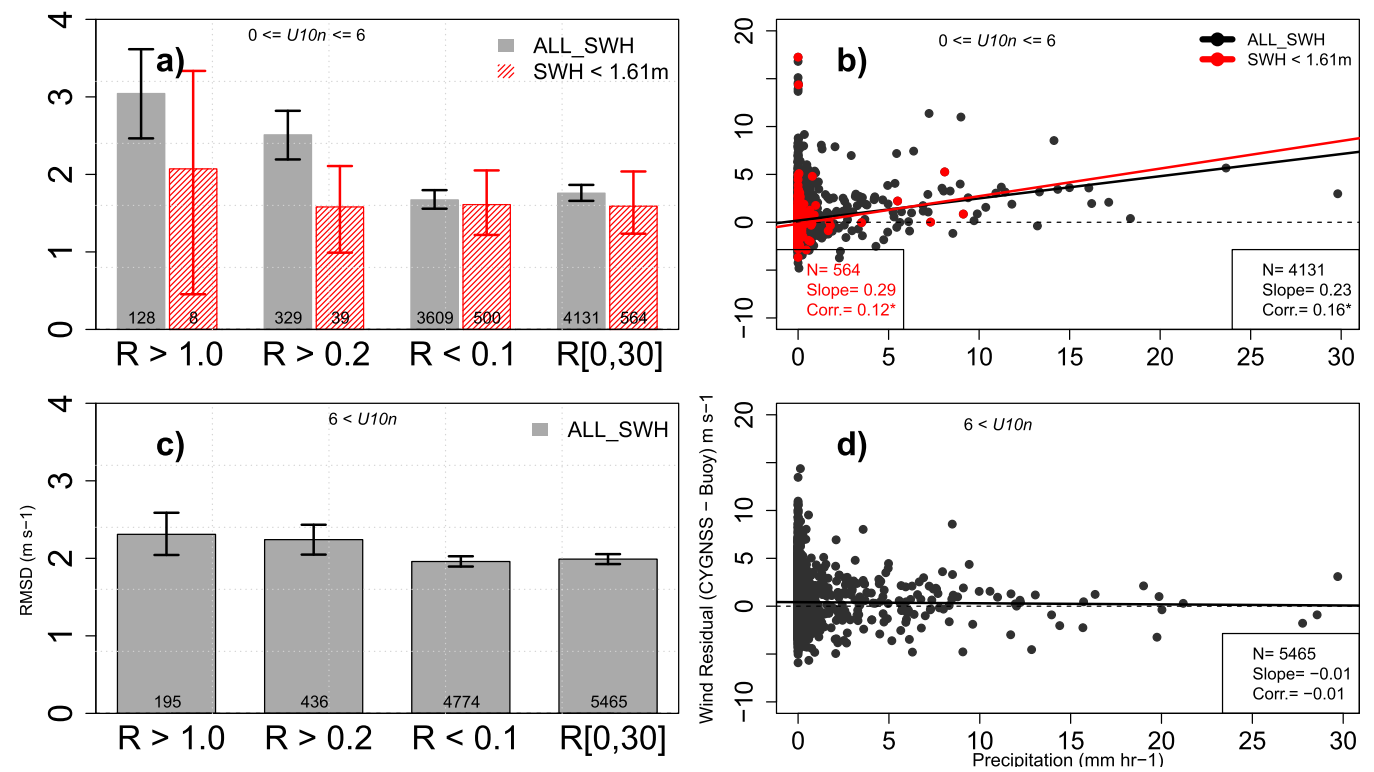

FIG. 7. (a),(c) RMSD (indicated by bars) and (b),(d) scatterplot of CYGNSS winds at the analyzed buoys (negative means buoy values are higher) as functions of buoy precipitation rate at different rain $\left(R\right.$; in $\left.\mathrm{mm} \mathrm{h}^{-1}\right)$ conditions. $U_{10 \mathrm{n}}$ is the buoy equivalent neutral wind at $10-\mathrm{m}$ height and $\mathrm{SWH}$ is the significant wave height. Also the best-fit linear regression lines onto the scatterplots are shown in (b) and (d). The black bars and lines shows data in all wave conditions, whereas the red color is for the filtered data ( $\mathrm{SWH}<1.61 \mathrm{~m})$. The error bars correspond to the $95 \%$ confidence limit estimated via the bootstrap method. Matchup samples are illustrated by number on each bar.

significant. The increased RMSD in CYGNSS winds during the cold-pool periods provides motivation to examine the dependence of the residuals on the cold-pool intensity. To this end, the slope and correlation coefficients were estimated from the wind residuals as a function of maximum temperature decrease $(\Delta T)$ during the cold-pool periods. In general, the near-surface air temperature is expected to decrease and attain a peak value during a mature stage of a convective cold pool. The parameter $\Delta T$, therefore, can be related to the intensity of a convective downdraft that likely passed over a buoy location or its immediate vicinity. The observed relationship between the wind residuals and the cold-pool intensity shows a slight increasing slope with increasing cold-pool intensity (Fig. 8b). Given the slope and correlation values, it indicates a small, but not statistically significant, dependency on the cold-pool intensity.

\section{e. Dependency on the spacecraft and antenna configurations}

Two downward-looking science-based antennas are mounted on each CYGNSS spacecraft, one directed starboard of the
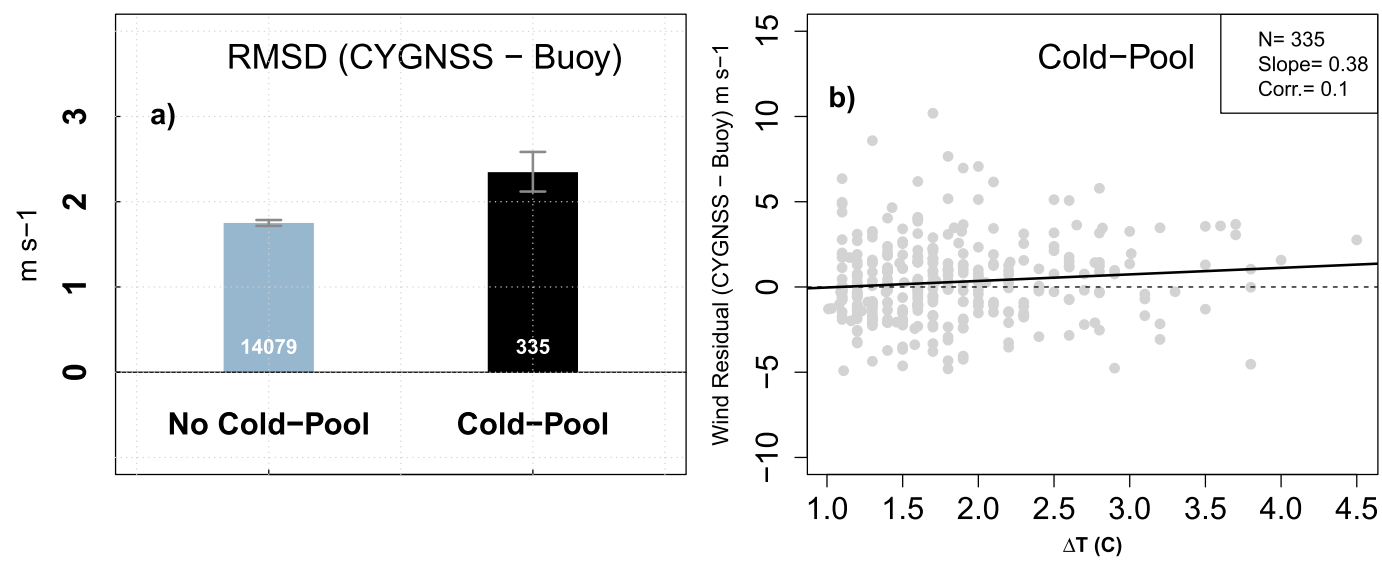

FIG. 8. (a) RMSD between CYGNSS and buoys winds under cold-pool and no-cold-pool conditions (during 2017-18). The error bars represent the $95 \%$ confidence interval estimated by the bootstrapping approach. (b) Wind residuals as functions of the cold-pool intensity. Also shown are best-fit lines onto the scatterplots. Sample size is given by numbers on the bars in (a). 

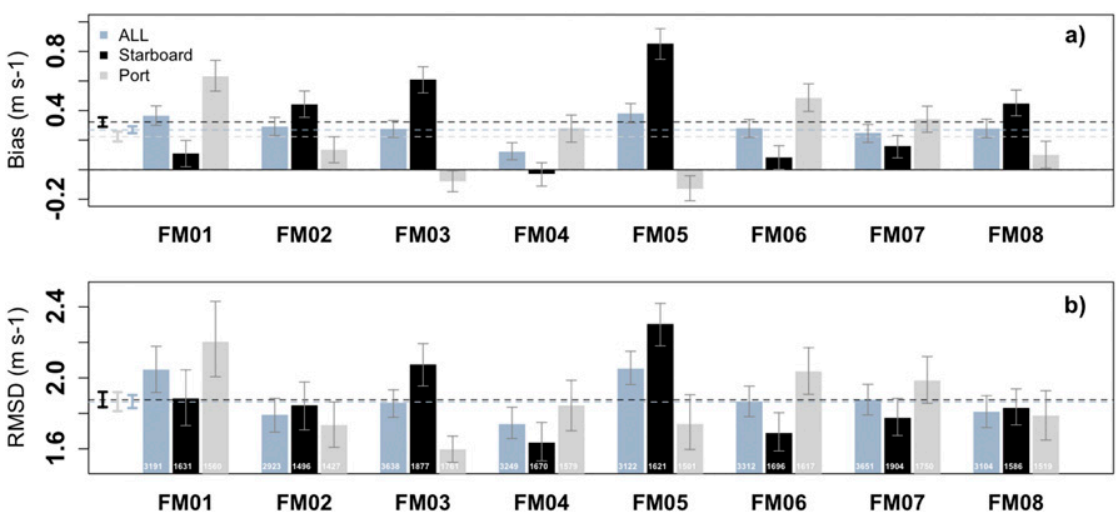

FIG. 9. (a) Bias and (b) RMSD between CYGNSS and buoy winds in each CYGNSS spacecraft (FM01 to FM08), for antenna (starboard and port), and for combined antenna ("ALL"). Sample size is given by the numbers on each bar in (b). Horizontal dashed lines are the combined spacecraft bias value in (a) and RMSD in (b), whereas the error bars represent the $95 \%$ confidence interval estimated by the bootstrapping (random sampling at 1000 times with replacement) approach.

subsatellite track and the other directed port, to provide the observations used to retrieve wind speeds. Differences in the precision and bias of wind estimates made by the two antennas and across the eight CYGNSS spacecraft (FM01 to FM08) are considered here.

The validation results indicate a clear tendency of positive wind bias in all spacecrafts (cf. Fig. 9a). However, the magnitude and sign of the bias varies between the antennas, and in some cases differs significantly from the mean bias value of $0.4 \mathrm{~m} \mathrm{~s}^{-1}$ (Fig. 9a, dashed line). The three largest biases are found for the starboard antenna on FM05 $\left(+0.9 \mathrm{~m} \mathrm{~s}^{-1}\right)$, starboard antenna on FM03 $\left(+0.6 \mathrm{~m} \mathrm{~s}^{-1}\right)$, and port antenna on FM01 $\left(+0.6 \mathrm{~m} \mathrm{~s}^{-1}\right)$. Differences in RMSD can also be seen across the eight CYGNSS spacecrafts, with the highest values exhibited by the starboard antennas on FM03 and FM05 ( 2 and $2.3 \mathrm{~m} \mathrm{~s}^{-1}$, respectively), and the port antennas on FM01 $\left(2.2 \mathrm{~m} \mathrm{~s}^{-1}\right)$ and FM06 $\left(2 \mathrm{~m} \mathrm{~s}^{-1}\right)$. Between these two statistics, the greatest outlier of the group is probably FM05. In addition, relatively small but significant differences in bias between starboard and port antennas $\left(\sim 0.2 \mathrm{~m} \mathrm{~s}^{-1}\right)$ were also found when categorizing the data for the Northern versus Southern Hemisphere tropics. The port antennas are directed largely to the north of the subsatellite track whereas the starboard antennas are directed largely to the south. This results in an asymmetric sampling of northern and Southern Hemisphere oceans between them. It is therefore possible that the observed differences in retrieval bias may be related to geophysicaldriven biases associated with north-south asymmetries in the tropics, such as exhibited by the intertropical convergence zone (ITCZ; Waliser and Jiang 2015). However, all eight spacecraft have very similar northern versus Southern Hemisphere sampling properties and the antenna-dependent biases do not follow a consistent trend across the eight spacecraft, so it is more likely the differences in bias, both between antennas and between spacecraft, are caused by residual errors in the engineering calibration, which is performed individually for each spacecraft and antenna. This is an ongoing area of investigation by the CYGNSS project team and the results presented here should be considered only as diagnostic features of the performance.

\section{Summary and conclusions}

Cyclone Global Navigation Satellite System (CYGNSS) wind estimates were compared with winds observed by tropical moored buoy arrays over a period of $\sim 27.5$ months. The results showed that, in general, CYGNSS captures the wind speed distributions effectively. Comparisons between the collocated buoy and CYGNSS wind speeds showed a general agreement along the 1:1 line globally and in each ocean basin (Fig. 2). However, there are some discrepancies, especially at the lower and higher observed extreme values of the wind speeds. For example, the CYGNSS bias is small and positive (i.e., $<+0.5 \mathrm{~m} \mathrm{~s}^{-1}$ ) at wind speeds less than $3 \mathrm{~m} \mathrm{~s}^{-1}$, near zero at wind speeds ranging between approximately 3 and $9 \mathrm{~m} \mathrm{~s}^{-1}$, and negative at higher wind speeds (Fig. 3a). Ruf et al. (2018) suggested that the decrease in sensitivity of the geophysical model function (GMF) with increasing wind speeds is one of the main factors responsible for the error growth at high winds.

On the whole, CYGNSS wind retrievals meet the science mission requirements for all rain conditions (Fig. 1 in Ruf et al. 2019). However, the rain driven splashing effects are found to be significant at low wind speeds (Figs. 7a,b), which is consistent with the earlier rain sensitivity analyses of Asgarimehr et al. (2018) and Balasubramaniam and Ruf (2018, 2020). The differences can be expected from the predictions of the weak diffuse scattering model (Zavorotny and Voronovich 2000) at the low wind condition, and the downdraft of a convective system (Balasubramaniam and Ruf 2020). The downdraft effect can be sensed from the decreased performance of CYGNSS wind speeds under cold-pool environments (Fig. 8). Our analyses indicate that the rain effects are evident at high winds too (above the $12 \mathrm{~m} \mathrm{~s}^{-1}$; not shown), yet the sampling 
confidence is rather low. Therefore, considerable data are yet to be assessed for a robust conclusion of the rain effect at the high wind condition.

The retrieved winds are further evaluated in three distinct oceanic regions: Indian, Pacific, and Atlantic (Fig. 1). Similar CYGNSS wind error characteristics are observed for all three regions. While the global comparisons between CYGNSS winds and buoy measurements are generally consistent with those observed in the regional scale (Figs. 3b-d), the Indian ocean exhibits a slightly larger error than in the Pacific and Atlantic Oceans (Figs. 2b-d). Because the wind speeds observed by CYGNSS are sensitive to rain at low wind speeds $\left(<\sim 6 \mathrm{~m} \mathrm{~s}^{-1}\right)$ and lower wind speeds are observed in the Indian and west Pacific Oceans, it is likely that additional errors are introduced in this region.

It is worth noting that the bias dependency is positive and yielded magnitudes of same order at both the unstable (Figs. $5 \mathrm{~d}$ and 6) and stable (Fig. 5d) atmosphere. While the atmosphere is found to be mostly unstable to nearly neutral over the tropical ocean, the wind bias dependency on stability suggests that care must be taken while analyzing the CYGNSS winds in a stable atmosphere. The dependency is found to be at a minimum in near-neutral conditions. Our analysis further reveals that by CYGNSS wind speeds exhibit errors that are higher by $\sim 34 \%$ during cold-pool versus no-cold-pool events, albeit the number of cold-pool occurrences is very small compared to the number of no-cold-pool (Fig. 8a) cases. Since cold pools are often associated with wind gustiness and changes in the air-sea state, they can modify the signal received by CYGNSS (e.g., through roughening the sea surface). Moreover, the influences of response time from the sea state to the CYGNSS wind estimates are crucial. Recently D. D. Chen et al. (2016) estimated that the CYGNSS response time from a change in the wind to a discernible change in the wave spectrum is about 0.4 to $1.8 \mathrm{~h}$. Given the fact that a cold pool is a short time-scale process (often considered as subhourly scale) and its boundaries move fast, the differences in errors in the CYGNSS wind speeds for no-cold-pool versus coldpool may correspond to the signal response time of the sea state that may not be accounted for in the wind retrieval process. A further independent analysis (not shown here) revealed that the uncertainty of the RMSD in CYGNSS winds is comparable with the estimated RMSD values by two different sensors [e.g., the Advanced Scatterometer (ASCAT-A and ASCAT-B)]. The similar error pattern, specifically in a cold-pool-type environment, in different sensors leads one to wonder about the validity of the reference data, e.g., the buoy wind height adjustment, which followed the assumption that the vertical wind profile is logarithmic in nature. It appears that interpretations of the error characteristics during the cold pool are not straightforward and require further investigations.

Aside from the environmental and geophysical effects, a potential source of uncertainty in the CYGNSS retrieved winds can be attributed to characterization of its hardware and engineering calibration errors. These are an active area of research by the CYGNSS community. Notwithstanding the error characteristics identified in this study, and the associated caveats in the interpretation of the results, comparison between CYGNSS wind speed estimates and buoy measurements indicates considerable utility of the CYGNSS surface wind data. The dense spatial and temporal sampling, compared with other space-borne wind sensing missions, may help to reveal the complexities of the air-sea interaction in relatively undersampled. While the present wind retrieval uncertainty satisfies the mission specific requirement for wind speeds below $20 \mathrm{~m} \mathrm{~s}^{-1}$, there is a considerable scope for further improvement, and upcoming revisions to the algorithms are expected to further reduce the errors in the CYGNSS estimated winds. For instance, efforts have been made to perform a bias adjustment and trackwise correction, and to utilize improved training datasets to generate the CYGNSS GMF for the level-2 wind speed product. This significantly removed spurious trend in the retrieved wind. Initial results from the new wind speed product (version 3.0) are promising, and updates to are expected to appear publicly on the JPL PO.DAAC web portal in the near future.

Acknowledgments. The authors acknowledge Jet Propulsion Laboratory (JPL) for providing computational facilities. SA express his sincere thanks to Dr. W.T. Liu (JPL) and Dr. Valery Zavorotny (Retired, NOAA/OAR/ESRL) for stimulating discussions on rain and stability effects. Thanks are also extended to Dr. Kenneth Connell (NOAA/PMEL) for the buoy data support. DEW's and DJP's contributions to this study were carried out on behalf of the Jet Propulsion Laboratory, California Institute of Technology, under a contract with the National Aeronautics and Space Administration. The NOAA/PMEL contribution number is 5072 . Finally, we thank the two anonymous reviewers for their constructive comments and suggestions that significantly improved the quality of this manuscript.

\section{REFERENCES}

Asgarimehr, M., V. U. Zavorotny, J. Wickert, and S. Reich, 2018: Can GNSS reflectometry detect precipitation over oceans? Geophys. Res. Lett., 45, 12 585-12 592, https://doi.org/10.1029/ 2018GL079708.

Balasubramaniam, R., and C. S. Ruf, 2018: Improved calibration of CYGNSS measurements for downbursts in the intertropical convergence zone. Int. Geosciences and Remote Sensing Symp., Valencia, Spain, IEEE, 3987-3990, https://doi.org/ 10.1109/IGARSS.2018.8517571.

$\longrightarrow$, and - 2020: Characterization of rain impact on L-band GNSS-R ocean surface measurements. Remote Sens. Environ., 239, 111607, https://doi.org/10.1016/j.rse.2019.111607.

Bourlès, B., and Coauthors, 2008: The PIRATA program: History, accomplishments, and future directions. Bull. Amer. Meteor. Soc., 89, 1111-1126, https://doi.org/10.1175/2008BAMS2462.1.

Boutin, J., and J. Etcheto, 1990: Seasat scatterometer versus scanning multichannel microwave radiometer wind speeds: A comparison on a global scale. J. Geophys. Res., 95, 22 27522 288, https://doi.org/10.1029/JC095iC12p22275.

Bretherton, C. S., M. Widmann, V. P. Dymnikov, J. M. Wallace, and I. Bladé, 1999: The effective number of spatial degrees of freedom of a time-varying field. J. Climate, 12, 1990-2009, https://doi.org/10.1175/1520-0442(1999)012<1990:TENOSD> 2.0.CO;2. 
Chandra, A. S., P. Zuidema, S. Krueger, A. Kochanski, S. P. de Szoeke, and J. Zhang, 2018: Moisture distributions in tropical cold pools from equatorial Indian Ocean observations and cloud-resolving simulations. J. Geophys. Res. Atmos., 123, 11 445-11 465, https://doi.org/10.1029/2018JD028634.

Chen, D. D., C. S. Ruf, and S. T. Gleason, 2016: Response time of mean square slope to wind forcing: An empirical investigation. J. Geophys. Res. Oceans, 121, 2809-2823, https://doi.org/ 10.1002/2016JC011661.

Chen, S. S., and Coauthors, 2016: Aircraft observations of dry air, the ITCZ, convective cloud systems, and cold pools in MJO during DYNAMO. Bull. Amer. Meteor. Soc., 97, 405-423, https://doi.org/10.1175/BAMS-D-13-00196.1.

Crespo, C., D. J. Posselt, and S. Asharaf, 2019: Surface heat flux product development. Remote Sens., 11, 2294, https://doi.org/ 10.3390/rs11192294.

Cronin, M. F., C. Fairall, and M. J. McPhaden, 2006: An assessment of buoy derived and numerical weather prediction surface heat fluxes in the tropical Pacific. J. Geophys. Res., 111, C06038, https://doi.org/10.1029/2005JC003324.

de Szoeke, S. P., E. D. Skyllingstad, P. Zuidema, and A. S. Chandra, 2017: Cold pools and their influence on the tropical marine boundary layer. J. Atmos. Sci., 74, 1149-1168, https:// doi.org/10.1175/JAS-D-16-0264.1.

Draper, D. W., and D. G. Long, 2004: Evaluating the effect of rain on SeaWinds scatterometer measurements. J. Geophys. Res., 109, C02005, https://doi.org/10.1029/2002JC001741.

Eastin, M. D., T. L. Gardner, M. C. Link, and K. C. Smith, 2012: Surface cold pools in the outer rainbands of Tropical Storm Hanna (2008) near landfall. Mon. Wea. Rev., 140, 471-491, https://doi.org/10.1175/MWR-D-11-00099.1.

Ebuchi, N., H. C. Graber, and M. J. Caruso, 2002: Evaluation of wind vectors observed by QuickSCAT/SeaWinds using ocean buoy data. J. Atmos. Oceanic Technol., 19, 2049-2062, https:// doi.org/10.1175/1520-0426(2002)019<2049:EOWVOB >2.0.CO;2.

Edson, J. B., and Coauthors, 2013: On the exchange of momentum over the open ocean. J. Phys. Oceanogr., 43, 1589-1610, https://doi.org/10.1175/JPO-D-12-0173.1.

Engerer, N. A., D. J. Stensrud, and M. C. Coniglio, 2008: Surface characteristics of observed cold pools. Mon. Wea. Rev., 136, 4839-4849, https://doi.org/10.1175/2008MWR2528.1.

Fairall, C. W., E. F. Bradley, J. E. Hare, A. A. Grachev, and J. B. Edson, 2003: Bulk parameterization of air-sea fluxes: Updates and verification for the COARE algorithm. J. Climate, 16, 571-591, https://doi.org/10.1175/1520-0442(2003)016<0571: BPOASF $>2.0 . \mathrm{CO} ; 2$.

Habib, E., W. F. Krajewski, V. Nespor, and A. Kruger, 1999: Numerical simulation studies of rain gage data correction due to wind effect. J. Geophys. Res., 104, 19723-19733, https:// doi.org/10.1029/1999JD900228.

Janowiak, J., B. Joyce, and P. Xie, 2017: NCEP/CPC L3 half hourly $4 \mathrm{~km}$ global $(60 \mathrm{~S}-60 \mathrm{~N})$ merged IR V1. GES DISC, accessed 4 July 2019, https://doi.org/10.5067/p4hzb9n27eku.

Kilpatrick, T. J., and S. P. Xie, 2015: ASCAT observation of downdrafts from mesoscale convective systems. Geophys. Res. Lett., 42, 1951-1958, https://doi.org/10.1002/2015GL063025.

Koschmieder, H., 1934: Methods and results of definite rain measurements. Mon. Wea. Rev., 62, 5-7, https://doi.org/10.1175/ 1520-0493(1934)62<5:MARODR >2.0.CO;2.

Le Méhauté, B. L., and T. Khangaonkar, 1990: Dynamic interaction of intense rain with water waves. J. Phys. Oceanogr., 20, 1805-1812, https://doi.org/10.1175/1520-0485(1990)020<1805: DIOIRW $>2.0 . \mathrm{CO} ; 2$.
Liu, W. T., 1984: The effects of the variations in sea surface temperature and atmospheric stability in the estimation of average wind speed by SEASAT-SASS. J. Phys. Oceanogr., 14, 392-401, https://doi.org/10.1175/1520-0485(1984)014<0392: TEOTVI $>2.0 . \mathrm{CO} ; 2$.

_, K. B. Katsaros, and J. A. Businger, 1979: Bulk parameterization of the air-sea exchange of heat and water vapor including the molecular constraints at the interface. J. Atmos. Sci., 36, 1722-1735, https://doi.org/10.1175/1520-0469(1979) 036<1722:BPOASE $>2.0$.CO;2.

Marzano, F., L. Roberti, and A. Mugnai, 2000: Impact of rainfall incoherent backscattering upon radar echoes above $10 \mathrm{GHz}$. Phys. Chem. Earth, 25, 943-948, https://doi.org/10.1016/S14641909(00)00130-1.

McCarty, B. J., and J. H. Churnside, 2016: Comparing near surface measurements of wind speed and direction over the Indian Ocean from lidar and scatterometer, and results from predictive study using the wind shear power law and the surface roughness log law to model upper level winds from near surface measurements. NOAA Tech. Memo. OAR ESRL-CSD0001, 27 pp., https://doi.org/10.7289/V5X63JZV.

McPhaden, M. J., and Coauthors, 1998: The Tropical OceanGlobal Atmosphere (TOGA) observing system: A decade of progress. J. Geophys. Res., 103, 14 169-14240, https://doi.org/ 10.1029/97JC02906.

— for African-Asian-Australian Monsoon Analysis and Prediction. Bull. Amer. Meteor. Soc., 90, 459-480, https://doi.org/10.1175/ 2008BAMS2608.1.

Mears, C. A., D. K. Smith, and F. J. Wentz, 2001: Comparison of special sensor microwave imager and buoy-measured wind speeds from 1987 to 1997. J. Geophys. Res., 106,11 719-11 729, https://doi.org/10.1029/1999JC000097.

Milliff, R. F., J. Morzel, D. B. Chelton, and M. H. Freilich, 2004: Wind stress curl and wind stress divergence biases from rain effects on QSCAT surface wind retrievals. J. Atmos. Oceanic Technol., 21, 1216-1231, https://doi.org/10.1175/1520-0426(2004) $021<1216$ :WSCAWS $>2.0$.CO; 2 .

Nešpor, V., and B. Sevruk, 1999: Estimation of wind-induced error of rainfall gauge measurements using a numerical simulation. J. Atmos. Oceanic Technol., 16, 450-464, https://doi.org/ 10.1175/1520-0426(1999)016<0450:EOWIEO > 2.0.CO;2.

Peng, G., H.-M. Zhang, H. P. Frank, J.-R. Bidlot, M. Higaki, S. Stevens, and W. R. Hankins, 2013: Evaluation of various surface wind products with OceanSITES buoy measurements. Wea. Forecasting, 28, 1281-1303, https://doi.org/10.1175/WAFD-12-00086.1.

Portabella, M., A. Stoffelen, W. Lin, A. Turiel, A. Verhoef, J. Verspeek, and J. Ballabrera-Poy, 2012: Rain effects on ASCAT-retrieved winds: Toward an improved quality control. IEEE Trans. Geosci. Remote Sens., 50, 2495-2506, https:// doi.org/10.1109/TGRS.2012.2185933.

Provod, M., J. H. Marsham, D. J. Parker, and C. E. Birch, 2016: A characterization of cold pools in the West African Sahel. Mon. Wea. Rev., 144, 1923-1934, https://doi.org/10.1175/MWR-D15-0023.1.

Quilfen, Y., and A. Bentamy, 1994: Calibration/validation of ERS-1 scatterometer precision products. Int. Geoscience and Remote Sensing Symp., Pasadena, CA, IEEE, 945-947, https:// doi.org/10.1109/IGARSS.1994.399308.

Rowe, A. K., and R. A. Houze, 2015: Cloud organization and growth during the transition from suppressed to active MJO conditions. J. Geophys. Res. Atmos., 120, 10324-10350, https://doi.org/10.1002/2014JD022948. 
Ruf, C. S., and R. Balasubramaniam, 2019: Development of the CYGNSS geophysical model function for wind speed. IEEE J. Sel. Top. Appl. Earth Obs. Remote Sens., 12, 66-77, https:// doi.org/10.1109/JSTARS.2018.2833075.

_, and Coauthors, 2016: CYGNSS Handbook. 1st ed. Michigan Publishing, $154 \mathrm{pp}$.

- S. Gleason, and D. S. McKague, 2018: Assessment of CYGNSS wind speed retrieval uncertainty. IEEE J. Sel. Topics Appl. Earth Obs. Remote Sens., 12, 87-97, https:// doi.org/10.1109/JSTARS.2018.2825948.

_ , S. Asharaf, R. Balasubramaniam, S. Gleason, T. Lang, D. McKague, D. Twigg, and D. Waliser, 2019: In-orbit performance of the constellation of CYGNSS hurricane satellites. Bull. Amer. Meteor. Soc., 100, 2009-2023, https://doi.org/10.1175/ BAMS-D-18-0337.1.

Serra, Y. L., P. A'hearn, H. P. Freitag, and M. J. McPhaden, 2001: Atlas self-siphoning rain gauge error estimates. J. Atmos. Oceanic Technol., 18, 1989-2002, https://doi.org/10.1175/15200426(2001)018<1989:ASSRGE>2.0.CO;2.

Tournadre, J., and Y. Quilfen, 2003: Impact of rain cell on scatterometer data: 1 . Theory and modeling. J. Geophys. Res., 108, 3225, https://doi.org/10.1029/2002JC001428.

Waliser, D. E., and C. Gautier, 1993: Comparison of buoy and SSMI/ I-derived wind speeds in the tropical Pacific. TOGA Note 12, $7 \mathrm{pp}$.

-_, and X. Jiang, 2015: Intertropical convergence zone. Encyclopedia of Atmospheric Sciences, Vol. 6, 2nd ed., Elsevier, 121-131.

Weissman, D. E., and M. A. Bourassa, 2008: Measurements of the effect of rain-induced sea surface roughness on the QuikSCAT scatterometer radar cross section. IEEE Trans. Geosci. Remote Sens., 46, 2882-2894, https://doi.org/10.1109/TGRS.2008.2001032.
- - - , and J. Tongue, 2002: Effects of rain rate and wind magnitude on SeaWinds scatterometer wind speed errors. J. Atmos. Oceanic Technol., 19, 738-746, https://doi.org/ 10.1175/1520-0426(2002)019<0738:EORRAW>2.0.CO;2.

—, B. W. Stiles, S. M. Hristova-Veleva, D. G. Long, D. K. Smith, K. A. Hilburn, and W. L. Jones, 2012: Challenges to satellite sensors of ocean winds: Addressing precipitation effects. J. Atmos. Oceanic Technol., 29, 356-374, https://doi.org/ 10.1175/JTECH-D-11-00054.1.

Whiteman, C. D., S. Zhong, W. J. Shaw, J. M. Hubbe, X. Bian, and J. Mittelstadt, 2001: Cold pools in the Columbia Basin. Wea. Forecasting, 16, 432-447, https://doi.org/10.1175/1520-0434(2001) $016<0432$ :CPITCB $>2.0$.CO;2.

Yokoi, S., M. Katsumata, and K. Yoneyama, 2014: Variability in surface meteorology and air-sea fluxes due to cumulus convective systems observed during CINDY/DYNAMO. J. Geophys. Res. Atmos., 119, 2064-2078, https://doi.org/ 10.1002/2013JD020621.

Yu, L., and X. Jin, 2012: Buoy perspective of a high-resolution global ocean vector wind analysis constructed from passive radiometers and active scatterometers (1987-present). J. Geophys. Res., 117, C11013, https://doi.org/10.1029/2012JC008069.

Zavorotny, V. U., and A. G. Voronovich, 2000: Scattering of GPS signals from the ocean with wind remote sensing application. IEEE Trans. Geosci. Remote Sens., 38, 951-964, https:// doi.org/10.1109/36.841977.

Zeng, X., M. Zhao, and R. E. Dickinson, 1998: Intercomparison of bulk aerodynamic algorithms for the computation of sea surface fluxes using TOGA COARE and TAO data. J. Climate, 11, 2628-2644, https://doi.org/10.1175/1520-0442(1998)011<2628: IOBAAF $>2.0 . \mathrm{CO} ; 2$. 